\title{
Review Paper: Developing a Parent's Early Telehealth Program for Stuttering Children Younger Than 4 Years and Assessing Its Validity
}

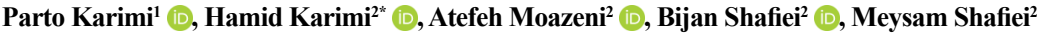

1. Student Research Committee, School of Rehabilitation Sciences, Isfahan University of Medical Sciences, Isfahan, Iran.

2. Department of Speech Therapy, School of Rehabilitation Sciences, Isfahan University of Medical Sciences, Isfahan, Iran

\begin{tabular}{|c|c|}
\hline \multirow{3}{*}{$\begin{array}{l}\text { Use your device tos can } \\
\text { and read the article online }\end{array}$} & ditation: Karimi P, Karimi H, Moazeni A, Shafiei B, Shafiei M. Developing a Parent's Early Telehealth Program for Stut- \\
\hline & $\begin{array}{l}\text { tering Children Younger Than } 4 \text { Years and Assessing Its Validity. Journal of Modern Rehabilitation. 2019; 13(1):11-22. http:// } \\
\text { dx.doi.org/10.32598/JMR.13.1.11 }\end{array}$ \\
\hline & doif http://dx.doi.org/10.32598/JMR.13.1.11 \\
\hline
\end{tabular}

Article info:

Received: 10 Jul 2018

Accepted: 23 Nov 2018

Available Online: 01 Jan 2019

\section{Keywords:}

Stuttering, Children,

Telehealth, Early intervention,

Preschool children, Software

\section{A B S T RACT}

Introduction: Recent studies suggest that treatment should be begun immediately in children who have recently started to stutter. The purpose of this study was to design a telehealth application for parents of young children who stutter. It is an evidence-based treatment that can be administered from an early age compared to the current "wait and see" approaches.

Materials and Methods: This research involved a qualitative content analysis. At first, a comprehensive review was performed on different well-established therapeutic programs, and their main therapeutic components were extracted via several sessions held by our focused group. Subsequently, six independent stuttering experts and five parents of stutter children were asked to rate the program's items regarding its content and face validities by a 5-point Likert questionnaire. Finally, the entire program was used to form an easy to use, familyfriendly software.

Results: Seven therapeutic principles and five common factors were extracted from all available well-established stuttering treatment programs. They were designed in an easy to use software program. The final telehealth program was found to have a high face and content validities.

Conclusion: This program might be used in future clinical practice for stuttering children under the age Four. However, its efficacy has yet to be examined.

\section{Introduction}

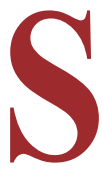

tuttering is a fluency disorder that mostly begins during childhood, especially between two and four years of age [1] (average age: 33 months) $[2,3]$. Stuttering affects $5 \%$ to
$8 \%$ of preschool children [4]. Out of them, approximately $60 \%-85 \%$ will spontaneously outgrow without any therapeutic intervention [3]. During the 24 month interval between the ages of two and four years, the incidence and prevalence of stuttering are similar, which means that both occurrence and recovery from stuttering are widespread

* Corresponding Author:

Hamid Karimi, PhD.

Address: Department of Speech-Language Pathology, School of Rehabilitation Sciences, Isfahan University of Medical Sciences, Isfahan, Iran. Tel: +98 (61) 449135404

E-mail:hkar7007@uni.sydney.edu.au 
during this golden time [3]. Although some people may argue that immediate treatment of stuttering is not necessary due to spontaneous recovery, we should know who is going to recover and also how long it will take $[2,3]$.

Moreover, because of the potentially destructive effects that stuttering may have on social development, mental health, and quality of life, stuttering specialists believe that treatment should be started as early as possible. It also should be noted that stuttering treatment is much more successful during preschool-age children compared to school-age ones [5-7]. Therefore, therapists are faced with a decision challenge. On the one hand, there are effective treatments for preschool stuttering children that are effective but time and money consuming; on the other hand, there is a chance for spontaneous recovery for some but not all the affected population. Based on the current existing therapy programs, there are different views on the process of starting stuttering treatment in preschool children.

The Lidcombe program is a stuttering treatment program for preschoolers with the highest level of research evidence [8]. Before 2016, the Lidcombe program providers announced (based on their research findings) that postponing a treatment program up to one year would not harm the outcome of the therapy $[8,9]$. They even reported that the treatment in older preschoolers in comparison to young children takes less time [10]. But after 2016, they suggested early stuttering therapy instead of the "wait and see" approach for two main reasons: 1 . The new studies have shown the chance of developing social anxiety and other mental health disorders due to stuttering from an early age [11]; 2 . Recent research findings indicate that the probability of spontaneous recovery in the first months after the onset of stuttering is much lower than the previous researchers' perceptions, as spontaneous recovery may take place over a much longer period [12]. As a result, the researchers now suggest beginning therapy as early as possible without any delay [13-15].

Parent-child interaction therapy is another treatment option for children of this age, which has proven research and acceptable evidence [16]. In the protocol of this program, all children will not be treated from the very beginning [17]. According to specific characteristics of stuttering children, only some children who are assumed more likely to become persistent stutterers will receive therapy, and the others will wait for about 12 months hoping for spontaneous recovery. However, the main problem is the current contradictory nature of evidence about the risk factors of being resistant to spontaneous recovery.

Other existing therapeutic programs for stuttering children, such as the family-focused stuttering program, the demand and capacity program, and the early intervention program do not provide a specific protocol for initiating or delaying stuttering therapy in preschool children $[11,18$ 20]. There is a wealth of evidence that stuttering treatment is useful in the treatment of preschool-age children and acts superior to spontaneous recovery $[21,22]$.

Therefore, it appears that there is no consensus on the best time to begin stuttering treatment and also about the best course of action during the so-called "wait and see" time. There is, of course, a consensus among all researchers to prevent secondary complications associated with stuttering, such as issues related to the mental health of children.

Arguably, studies have shown no significant differences between the efficacies of various stuttering treatment approaches. For example, the results of a recent study in the Netherlands on more than 100 stuttering children showed no significant difference between the stuttering severity decrease following either the Lidcombe or the program based on demand and capacity model [23]. Therefore, different standard treatments for stuttering children seem to have similar results in spite of having different approaches, techniques, strategies, and philosophies. Some researchers believe that some common factors exist among these treatments that made them all effective [24]. The same claim has long been proposed for psychological therapies [25-27].

In light of the above information, an interstitial approach in which the child starts an early easy-to-perform intervention program before suggesting the current time-consuming, costly structured, standardized program might be the right solution. Such a treatment program might get benefit from known common factors among different therapies. In this way, instead of having children receive direct treatment programs from early on or waiting for spontaneous recovery, a remote therapy program can be used that requires less direct visits to the clinic, and takes advantage of the skills and experiences of children's parents.

The new program is a family-centered program with no direct intervention for children. This program aims to cover risk factors of mental health disorders secondary to stuttering as social anxiety disorder. It also would increase the child's chances of stuttering reduction because it employs the common factors of current standard well-established stuttering treatments, while it demands less time, money, and resources from both the family and the health system.

Another vital topic for stuttering treatments is its delivery system. Since the proposed treatment aims to reduce the required resources, it cannot be a demanding weekly or intensive one-on-one treatment program. Therefore, other 
delivery treatment modes were considered. One of these methods is utilizing computer programs that are attractive, enjoyable, efficient, and applicable [28]. Considering the population distribution in the world, and creating an equal opportunity for all the families whose children have just begun to stutter regardless of where they live, a software computer program might be an ideal solution.

Stuttering telehealth programs have just focused on such well-established stuttering treatments for children or adults as the Lidcombe Program or the Camperdown Program, and no face-to-face or telehealth treatment is now available for those who have just begun to stutter, and for whom that their therapists are unsure whether they should undergo treatment or not [23, 29-32].

The proposed treatment plan aims at helping children who have recently started to stutter and are younger than four years. This treatment program aims to put these children on the path to recovery, while at the same time prevent them from mental health problems like social anxiety disorder. The major component of this program is its telehealth nature, which provides all families from all around the world with similar access to the treatment. The purpose of this study was to design this program and to evaluate its face and content validities.

\section{Materials and Methods}

This study was a descriptive and qualitative content analysis study in which a new early intervention program for young preschool-age children was designed, and its face and content validities were evaluated. The Ethics Committee of Isfahan University of Medical Sciences approved this study in 2017-2018. A focused group was formed to design the new stuttering treatment program. They were five experienced speech therapists with 2 to 15 years of clinical experience in the field of stuttering.

Some experienced speech pathologists and parents of children with stuttering were also invited to take part in this study to assess the face and content validities of the program. This group included six independent speech and language pathologists who were experts in the treatment of stuttering and five literate parents of preschoolers who had just previously started to stutter. Experts were chosen purposefully, but parents were recruited randomly. They were added one at a time until data saturation was met.

\section{Program design}

In the first step, a comprehensive review of all therapeutic programs published in journals and textbooks over the past
27 years (after 1990) was performed to design the new telehealth stuttering program. Besides, all reported telehealth programs in the field of speech therapy were reviewed. Table 1 summarizes the aim, target resources, and keywords used for this literature review.

The second step in the literature review was to review the available treatment programs in the focused group regarding their methods, results, and objectives to identify the currently available most evidence-based treatment approaches. The group also discussed and extracted principles and common factors among evidence-based stuttering programs. Furthermore, attempts were made to find out the most suitable telehealth delivery system in speech therapy based on previously published papers on preschool-age children.

\section{Data analysis method}

We used a content analysis approach to analyze the collected information extracted from literature and what obtained from five in-depth semi-structured interviews with the members of the focused group. The primary purpose of the interview with this group was to provide first-hand experience form a specialist group. The obtained information from this group enhanced the richness of data and improved the depth of data in a collaborative environment Then, the focused group was formed to discuss the new treatment's design and contents.

By further elucidating the findings, some interviews were conducted in person or by telephone with each member of the group. With the consent of the participants, all the talks were fully recorded, and notes were made in the field. Immediately after each interview, the researchers carefully listened to the recorded conversations several times. After listening, the essential items in the interviews were taken into consideration. Then, the transcribed verbatim was compared with the recordings to increase the accuracy and gain more control over the information provided. After this stage, the written information was analyzed by the content analysis method. This method involves extraction and systematic classification of codes and classes from raw data.

In this way, key concepts and hidden patterns were extracted and revealed, and data collection and analysis carried out simultaneously. Also, the primary codes of semantic and similar units were derived from literature related to different therapeutic approaches. Afterward, the codes were divided into abstract classes and key concepts subclasses based on the similarities and differences. 
Table 1. The results of reviewing the evidence-based resources published between 1990 and 2017

\begin{tabular}{|c|c|c|}
\hline \multicolumn{3}{|r|}{ Literature Review } \\
\hline \multirow{5}{*}{ The first search } & Objectives & $\begin{array}{l}\text { Extraction of stuttering treatments in preschool children with the most scientific and } \\
\text { clinical evidence }\end{array}$ \\
\hline & Keywords & $\begin{array}{l}\text { Protocol, stuttering, stammering, disfluency, preschool age, preschoolers, children, } \\
\text { treatment, therapy, intervention and stuttering therapy books }\end{array}$ \\
\hline & Data based & $\begin{array}{l}\text { ASHA (American Speech, Language, and Hearing Association website), Google Scholar, } \\
\text { Science Direct, PubMed, Springer, SpeechBITE }\end{array}$ \\
\hline & Total articles obtained & 22000 \\
\hline & Selected articles & $\begin{array}{c}\text { By studying the title and abstracts of the articles, } 200 \text { articles were searched and } \\
\text { studied }\end{array}$ \\
\hline \multirow{5}{*}{$\begin{array}{l}\text { The second } \\
\text { search }\end{array}$} & Objectives & Identifying and extracting common factors in preschool stuttering treatments \\
\hline & Keywords & $\begin{array}{l}\text { Common factors, similarities, stuttering, stammering, disfluency, preschool age, pre- } \\
\text { schoolers, children, treatment, therapy, intervention }\end{array}$ \\
\hline & Data based & $\begin{array}{l}\text { Protocol, stuttering, stammering, disfluency, preschool age, preschoolers, children, } \\
\text { treatment, therapy, intervention and stuttering therapy books }\end{array}$ \\
\hline & Total articles obtained & 100 \\
\hline & Selected articles & 2 \\
\hline \multirow{5}{*}{ The third search } & Objectives & Studying speech therapy and stuttering telehealth \\
\hline & Keywords & Telepractice, telehealth, speech therapy, stuttering, stammering, language, speech \\
\hline & Data based & $\begin{array}{l}\text { Protocol, stuttering, stammering, disfluency, preschool age, preschoolers, children, } \\
\text { treatment, therapy, intervention and stuttering therapy books }\end{array}$ \\
\hline & Total articles obtained & 13000 \\
\hline & Selected articles & 53 \\
\hline
\end{tabular}

In this way, the main concept of meaningful sentences was extracted in code form, and then code classification was started. All codes with a common concept were placed under a category and named. With each new interview, new categories could be revised, even merged or new classes created. In the next step, a supervisor reviewed the classifications and nominations. By sorting the classification, their main themes were extracted, and the relationships between classes were identified.

Qualitative research data and findings should be acceptable and reliable, and this issue depends on the collection of accurate data. Usually, interventions and observations in the methodology of research make data more acceptable. In this study, a peer review was used to examine the acceptability of data. In this method, the results and analyzes and the summary of the research are presented to several experts to know their complementary and critical views and to consider whether the researcher's understanding is similar to others.

\section{Content validity}

To determine the content validity of the program, six independent speech and language pathologists, including two psychologists, were asked to rate the items of the telehealth program. A total of ten files (one guide file and nine files related to program components) were sent to the participants. At the end of each file, tables of content validity were presented to the experts and asked them to answer to three sections of the scenario (stems of a question). The options related to each scenario and the content presented in each section were rated based on a 5-point Likert-type scale (very low, low, medium, high, very high), in terms of their relevance to the subject, as well as the necessity and the adequacy of each component of the program.

\section{Face validity}

To determine the face validity of the program, six independent speech and language experts and psychologists and five parents of stuttering children were asked to rate the items of this program. A total of ten files (one guide file 
and nine files related to program components) were sent to participants. At the end of each file, the tables of face validity were presented to the participants and asked them to answer three sections of the scenario (stems of a question). The options associated with each scenario and the content presented in each section were rated based on a 5-point Likert-type scale (very low, low, medium, high, very high) in terms of clarity and ambiguity in the writing of various components of the program.

\section{Statistical analysis}

To examine the face and content validities of treatment items, the descriptive statistics, including the range of scores and median score was used.

\section{Results}

\section{The designed program}

After reviewing both evidence-based therapeutic programs and internationally-known programs with reported clinical evidence published in books and papers in previous years, panel members selected five pediatric stuttering programs of the Lidcombe program, the parent-child interaction program, treatment obtained from the demand and capacity model, the family-focused therapy, and the early treatment program as the main programs. Then based on them, they designed the principles and framework of the new treatment program. Subsequently, based on the context of the literature and therapeutic applications, seven general principles were considered as the bases for the design of the new program (Table 2), along with the reasons for choosing these principles.

Inclusion criteria of the new stuttering treatment program

Based on the above principles and by reviewing the treatment goals at a meeting with the panel members, the new treatment program developers decided that the candidate children to the new program should have all the following three conditions:

Having speech disfluency (either natural disfluency or stuttering); Being under four years old (following principle seven of the program); Having experienced no unsuccessful stuttering treatment so far (following principles five and six of the program).

\section{Program goals}

Three objectives have been considered for this new treatment program: 1. Elimination of stuttering; 2. Reducing family concerns about the child's stuttering; 3 . Prevention of abnormal emotional, behavioral, and cognitive reactions of the child to stuttering, such as sensitivity to it, social anxiety, or secondary behaviors.

We specified five common factors among all of these programs after a careful review and comparison of five current therapeutic programs with scientific or clinical evidence that has the highest popularity in different countries and study of articles that examined the common factors of treatment programs (Based on principle 6 of the new program) (Table 3) [24, 34].

\section{Treatment outcome measures}

Similar to all current therapeutic programs, the new treatment program involves two types of assessments: 1 . An initial evaluation to check the children's inclusion criteria for this program; and 2. A final assessment of the success of the current treatment which consists of three groups of measures: Stuttering severity measures, a questionnaire that assesses the impacts of stuttering on preschoolers and parents, and the parents' attitude toward stuttering questionnaire (similar to what is used in the parent-child interaction program).

\section{Presenting the new treatment program}

Considering the principles one, two and four of the treatment program, a problem-based learning method was designed as a Windows desktop application program. This program is presented as different scenarios of hypothetical patients, which provides the parents with such opportunities to receive information through constructing mental status, allegory, and modeling. Since the second principle of the program is based on the reinforcement of parent's knowledge, scenarios can help represent the parents' knowledge, and inviting the family to face the challenge, solve the problems, from which creates an incentive to find the best solution to the situation.

Each scenario consists of three main parts: 1 . The question stem that describes the hypothetical scenario; 2 . Multiple choices about the situation and the family is asked to choose the best answers; and 3. A group of feedbacks that the family will receive after selecting the options. This feedbacks first gives information to parents whether their answers are right or wrong and then continues with various media, such as audio, video, text, in which more information is introduced to expand or consolidate their knowledge in that area. Scenario-based learning (based on a problem-based learning approach) not only helps to strengthen and develop the current understanding of the family but also helps improve 
Table 2. Principles of the new program and the reasons behind each principle

\section{Principles of the New Program}

Individuality

1 Reason: One of the common principles among all preschool programs is the individuality of the program [11, 33, 34]. Individuality means that each person receives a service suited to the needs of the person [35].

The presentation of the program is based on identifying, highlighting, and strengthening family capabilities in the form of a familyfriendly program.

Reason: Families help their children even before being referred to the speech therapist. Therefore, it is necessary to identify and enhance those functions to improve the parent-child relationship, which is one of the goals of treatment [36]. This principle was con-

2 sidered through a family-friendly model. In this model, although the therapist is the primary decision-maker, families are involved in all treatment processes, including setting treatment goals. The principles of family-friendly programs include:

- Creating a positive relationship between parents and the child

- Receiving family feedbacks and suggestions on the treatment process

- Paying attention to the child as a member of the whole family [37].

3 Reason: By supervising the speech therapist, the program will not only ensure the correct implementation of the program but will also make the family feel better in terms of receiving support and patronage when necessary.

Availability of the treatment program to everyone

To achieve this goal, this program should be a remote program, needs a minimal visit to speech pathologists, and follows the open door policy.

Reason: Due to the vastness of the country and the population dispersion, and to provide an equal opportunity for the use

of families whose children have just begun to stutter, this program is a remote program and needs minimum number of clinic

visits, but at the same time adheres to the open door policy [11]. So the families can refer to the clinic with appointments

whenever they are concerned about their child's stutter and want to consult with the therapist. This policy reduces the concerns of families.

providing a stepped care service model

Reason: A stepped care service model contains two parts: providing the easiest and the least expensive effective treatment models at first, and then receiving more medical resources as it is needed. In other words, the treatment starts at the lowest cost and the simplest level, but if it is required, the higher references will become available for more healthcare resources.

5 This model serves to address the economic aspect of the program and prevents unnecessary services for individuals. The current program is associated with the minimum presence of the family at the clinic and the least amount of need for changes in the behavior of the child or family, and merely if the program failed to achieve its goals, the child would receive other applications that require more time and the exercises [11,24].

Treatment is based on common factors of current evidence-based practice in stuttering treatment for preschoolers. Reason: Previous research has shown that the results obtained from different stuttering treatments in preschool children are similar despite their very different therapeutic approaches [23, 24]. Based on the model of common treatment factors, some common factors make treatment programs useful. In other words, these factors are common among all the effective treatment programs for stuttering in preschool ages, and these are factors that make all treatments effective and eventually result in the same outcome [34].

The current program is an early intervention program.

7 Reason: This program will begin very soon and immediately after the onset of stuttering, because this program is the first step in the stepped care model of early stuttering treatment, and this program aims to avoid secondary complications to stuttering. Therefore, this program has been introduced as an early preventive program in the treatment of stuttering.

Table 3. Common factors in preschool stuttering programs

\section{Common Factors}

\begin{tabular}{lr}
\hline 1 & $\mathbf{5}$ Common Factors \\
\hline 2 & Continuous assessment of the child's speech disfluency \\
3 & Geving specific child-parent interactions \\
4 & Tiving the family the opportunity to express concerns about their child's stuttering \\
5 & Teaching problem-solving skills to parents to deal with stuttering issues
\end{tabular}




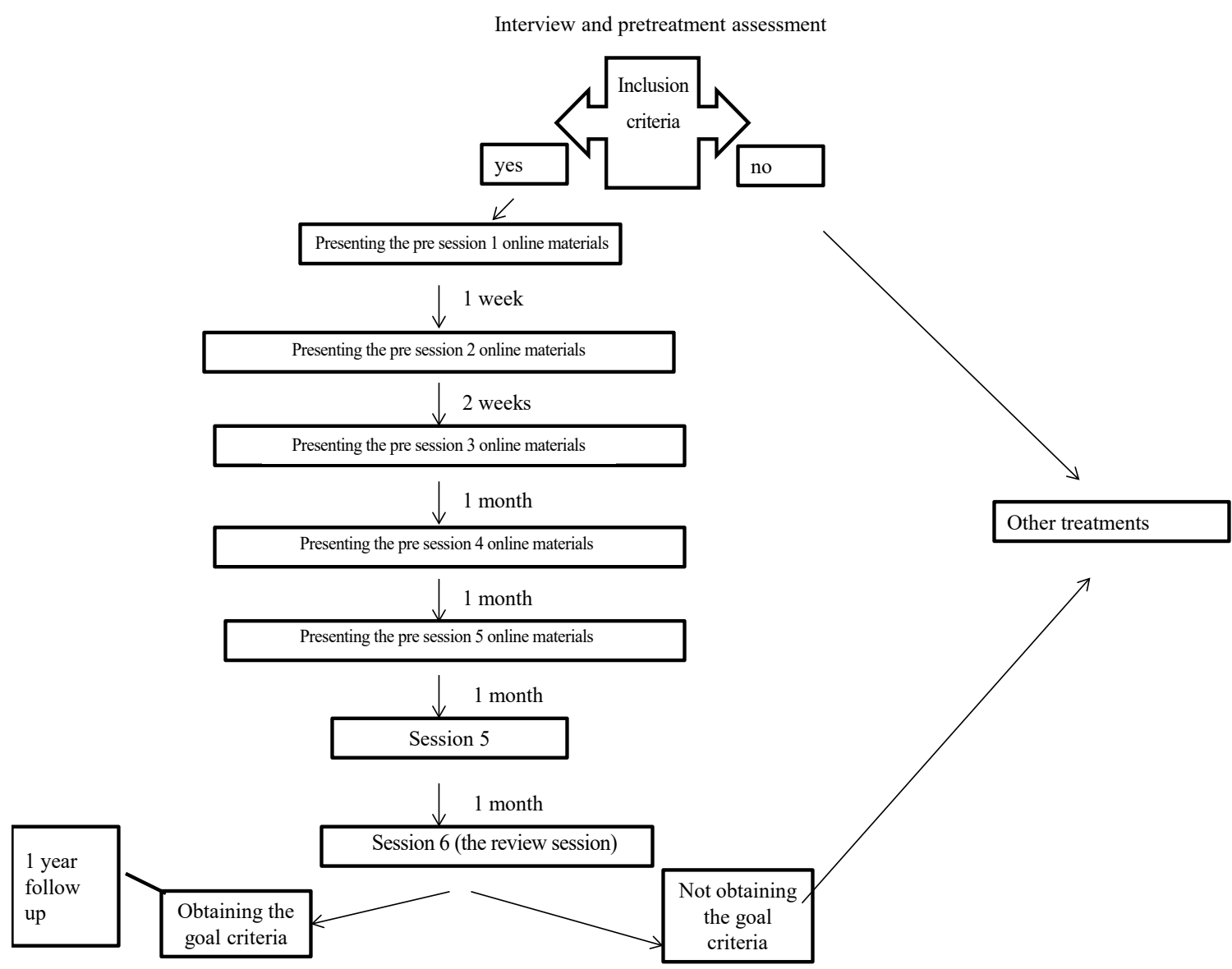

Figure 1. Flowchart for the program

family's problem-solving skills and confidence in solving future child's issues. Besides, the family can get the necessary information depending on the needs of the child by choosing different options and reading different scenarios.

Moreover, providing a remote therapeutic program which is under Windows desktop application program will make the application publicly available. An example of scenarios is given in appendix 1 .

The final program is designed to include a total of nine scenarios, 40 options, and 40 written, audio, or video feedback. The duration of the treatment is 4.5 months in total. The treatment is carried out in six sessions with the therapist in a face-to-face, distance, or combination of both formats so that the family can contact the therapist directly to express their concerns and resolve individual issues related to their child (based on common factor 4). In the first four sessions, the software content is given to the family in a row, and the remaining two sessions are solely for family-based problem solving, as shown in Figure 1.

\section{Content validity of the new treatment program}

According to six independent speech therapists, $85 \%$ of the program items were appropriate in terms of subject relevance and provided adequate training to achieve the desired objectives for this program. The specialists median scores given for each component of the program based on a 5 -point Likert scale ( $1=$ totally inappropriate and unrelated to the subject, and $5=$ completely relevant and necessary to the topic) was 5 , and the range of scores was 4 to 5 which implies good content validity of over $85 \%$ of program items. The other $15 \%$ of the new program components needed to be changed. For six items, although the median score was 4 , the range of scores obtained from independent judges was between 3 and 5 for three items and between 2 and 5 for the other three items. Therefore, these items were reviewed and revised according to the expert's ideas and reinstated.

\section{The face validity of the new treatment program}

According to parents of stuttering children and also six independent speech therapists of this study, $90 \%$ of the treatment items were clear, explicit, and comprehensible for readers; however, $10 \%$ of the items should be revised. 
Subsequently, the interviews were conducted about items that had median scores of less than 4 out of 5 , and based on expert comments, the changes were made to the wordings and then re-submitted to them for re-examination. Additionally, the items that had gained the median score of 4 out of 5 from the experts' point of view with at least a score of 3 or less from 2 experts or parents were also revised and corrected based on their opinions. The items then were resubmitted to experts who were finally approved by all five stuttering children's families and all six independent study experts.

\section{Designing the treatment program as a software}

After confirming the face and content validities of the program items, all program parts were sent to a programmer to be published as software. After drawing its algorithm and entering the data with the Visual Studio and NET tool and the $\mathrm{C}$ programming language under NET Framework, the final program was created by a specialist as a desktop software application that was used in the Windows operating system.

\section{Discussion}

The newly designed treatment program aims to help stuttering children who are younger than four years to have an opportunity to recover from it and at the same time, prevent the risk of mental health disorders such as social anxiety disorder. In other words, the goal is to create an early and interstitial program that is an alternative for the other two current options. The current options are either to enter children into a structured lengthy treatment program immediately or to wait and see in the hope of spontaneous recovery. The latter option is problematic since it is unknown who will outgrow from the disorder, and the former one imposes some unnecessary costs to families and a burden on the health system.

Since $95 \%$ of children start to stutter from an early age between the ages of two and four, and our goal is to provide early treatment, our target community are children under the age four [3]. This is different from other treatment programs that target all preschool-age children, and even some such as the Lidcombe Program that covers younger schoolage children [11].

This program is based on common factors that are shown to be effective in standard current stuttering programs of preschoolers. The common factors were taken from the Lidcombe Program, parent-child interaction program, early intervention program, family-focused program, and demand and capacity model program. These programs all have the common factors of continuous assessment of changes in stuttering severity, family education about stuttering, having a particular interaction time between the child and parents, giving families the opportunity to express their concerns, and teaching parents the problem-solving skills. The ultimate goals of the program are broadly based on the philosophy behind the program, including stuttering elimination, reducing family anxiety about stuttering, and the prevention of abnormal behavioral, emotional, or cognitive responses of the child to stuttering such as reacting to stuttering, social anxiety, and gestures. However, stuttering programs follow different goals for preschool-age children. Lidcombe Program mostly considers the severity of stuttering and aims to eliminate stuttering and does not assess the child and the family attitude [8]. On the other side, parentchild interaction program, family-focused, demand and capacity model, and the early intervention program consider attitude assessments as important part of their outcome measure $[20,18,36]$.

The new treatment program employed the "impact of stuttering on preschoolers and parents" questionnaire to assess the families' attitude toward stuttering. A continuous assessment of the stuttering severity of children is one of the common factors in stuttering treatment programs of this age, although there are different tools for this purpose. In treatment programs such as the Lidcombe program, the parent-child interaction program, and the early intervention program, Severity Rating (SR) is used to assess stuttering severity, which is a perceptual stuttering severity measure. However, in demand and capacity model, the Stuttering Severity Index (SSI) form is used in which the percent Syllable Stuttered (SS\%) is calculated $[19,38]$. Some studies have shown a close correlation between SR scores and $\mathrm{SS} \%$ (about 0.91), which suggests that these two measures can be used interchangeably [39]. However, the results obtained from other studies are different as these measures might be assumed different from each other [40]. There are many benefits of using SR scale.

Contrary to SS\%, SR implementation is convenient and free of charge, and needs no equipment or specialized training. This tool allows clinicians and stuttering people to discuss stuttering severity of the real-life environment and to monitor the changes in stuttering frequency throughout the day. SR scores are a common language between the therapist and the child's family to discuss the severity of stuttering and its changes over time [41-42]. On the other hand, the family can evaluate the child's speech whenever and wherever they are together without being the child aware of that. Also, SR scale seems to be more valid in comparison with $\mathrm{SS} \%$ as it provides a more comprehensive measure- 
ment of stuttering behavior, which covers the type and severity of stuttering moments and secondary behaviors [11].

Another common factor in all existing therapies for children is educating the family about stuttering. Almost all treatment plans provide general information to families about stuttering, the role of parents in stuttering, strategies when stuttering becomes severe, and how to talk about stuttering with a child $[8,18-20,36]$. The present program also includes a series of tutorials on these programs, such as how to deal with stressors, increasing the child's confidence, issues relating to the perfectionism of the child and parents, as well as the topic of bullying. Aside from the Lidcombe Program, these educations exist in some forms in other therapeutic applications.

Having a specific interaction time is the third common factor in all treatments in which the family pays a certain amount of time to interact with his or her child for a specific period. Although these activities vary in terms of duration and type among different therapeutic programs, the common point among all these treatments is the interactive period between the child and the parent(s). As with all other therapies, the current treatment program includes a 15-min daily interaction between the child and his or her parents. In this newly-developed treatment program, both parents need to spend time with the child, and for this purpose, both must be trained by the therapist.

Educating the parents is part of all existing therapeutic programs; however, the training in this new program, unlike other programs, can be virtual in which parents use the provision of a scenario and questions and answers, and eventually display a movie of one of the effective communications between the parent and the child.

The presentation of this program is based on a medical education and assessment system called the patient management problem system. In this method, the logical course of the problem-solving method is used in dealing with the problems that have arisen for the patient. This method includes features such as providing an overview of hypothetical patent, giving instant feedback, and using audio and video tutorials while answering options. In other words, the primary purpose of this method is to provide skills for collecting information, categorizing hypotheses, and ultimately solving the problem by parents. Regarding the purpose of the study, which is to provide education to families through problem-solving, and considering that problem-solving skills training is another common factor in various stuttering treatment for children, this approach seems to be an excellent way to achieve these goals.
In the telehealth programs offered for the stuttering treatment, the therapist uses the telephone or a webcam to provide one of the existing therapies, such as the Lidcombe Program or Camperdown Program [23, 30, 32]. The difference between the current program and previous programs is that some items are designed in the software that does not require direct interaction with the therapist, as well as a series of non-software sessions that allow parents to either face-to-face or remotely communicate with a therapist via telephone or videoconferencing. This capability not only helps families to get access to the therapy but also provides an opportunity for the parents to express their concerns and could directly share stuttering issues at that time so the therapist could solve the problems.

Although the whole program takes 4.5 months, only six sessions are needed to establish direct communication between parents and therapists, which can be done either by telephone or via the internet (Webcam), depending on the parents' desires and conditions. These sessions can be arranged in person if the parents feel the need and the terms of the appointment.

Regarding the design of the components of this program and with proper face and content validities, the new program seems to be a good program for early stuttering treatment in young children. It is evident, however, that to evaluate its effectiveness for extending this program to all children in this age range, further research should be undertaken to examine the efficacy of this program. The present application has the potential to be used as an early treatment plan before using the existing time-consuming and costly effective structured programs. So it does not only prevent secondary stuttering behaviors and mental health risks but also helps to eliminate stuttering early in children.

\section{Conclusion}

In general, the results of this study indicate that telehealth program items in all parts, including scenarios, scenario options, and feedback content have the satisfactory face and content validities which means that this program is ready to be used by several stuttering children's families to examine its effectiveness in future studies. Before generalizing the results of this study, its efficacy should be made apparent. This program is essentially a remote and family-based program that does not require the presence of a child, and software provides its therapeutic items. However, to express family concerns and solve individual problems of each family, which covers principle one, this program includes meetings as confrontational meetings or direct contact with the therapist, which can take place face to face or remotely. 


\section{Ethical Considerations}

\section{Compliance with ethical guidelines}

The recordings involving the opinion of specialists, patients, and their families have been kept confidential. The participation of specialists and parents of stuttering children in this program was also voluntarily.

\section{Funding}

The present paper was extract from the MSc. thesis of the first author, Parto Karimi, at department of speech therapy, school of Rehabilitation Sciences, Isfahan University of Medical Sciences, Isfahan.

\section{Authors contributions}

Conceptualization, methodology, investigation, writingreview and editing: All authors; Writing-original draft: Parto karimi.

\section{Conflict of interest}

The authors declare no conflict of interest

\section{Acknowledgements}

We are grateful to all independent speech pathologists and parents of stuttering children who cooperated with us throughout the study.

\section{References}

[1] Conture EG. Stuttering: Its nature, diagnosis, and treatment. London: Pearson; 2001.

[2] Yairi E, Ambrose N. Epidemiology of stuttering: 21 $1^{\text {st }}$ century advances. Journal of Fluency Disorders. 2013; 38(2):66-87. [DOI:10.1016/j.jfludis.2012.11.002] [PMID] [PMCID]

[3] Yairi E, Ambrose NG. Early childhood stuttering iPersistency and recovery rates. Journal of Speech, Language, and Hearing Research. 1999; 42(5):1097-112. [DOI:10.1044/jslhr.4205.1097] [PMID]

[4] Conture EG. Treatment efficacy stuttering. Journal of Speech, Language, and Hearing Research. 1996; 39(5):S18-S26. [DOI:10.1044/jshr.3905.s18] [PMID]

[5] Kingston M, Huber A, Onslow M, Jones M, Packman A. Predicting treatment time with the Lidcombe Program: Replication and meta-analysis. International Journal of Speech-language $\mathrm{Pa}$ thology. 2003; 38(2):165-77. [DOI:10.1080/1368282031000062882] [PMID]
[6] Prasse JE, Kikano GE. Stuttering: An overview. American Family Physician. 2008; 77(9):1271-6.

[7] Onslow M, Packman A, Harrison RE. The Lidcombe Program of early stuttering intervention: A clinician's guide. Sydney: Austin; 2003.

[8] Packman A, Onslow M, Attanasio J, Onslow M, Packman A, Harrison E. The timing of early intervention with the Lidcombe Program. The Lidcombe Program of early stuttering intervention: A clinical guide. 2003; 2003:41-55.

[9] Jones M, Onslow M, Harrison E, Packman A. Treating stuttering in young children: Predicting treatment time in the Lidcombe Program. Journal of Speech, Language, and Hearing Research 2000; 43(6):1440-50. [DOI:10.1044/jslhr.4306.1440] [PMID]

[10] Onslow M. Stuttering and its treatment: Eleven lectures. [Internet]. 2015 [Updated 2019 Nov 14]. Availble from: https:// sydney.edu.au/content/dam/corporate/documents/facultyof-medicine-and-health/health-sciences/health-sciences-research-brochure.pdf

[11] Saltuklaroglu T, Kalinowski J. How effective is therapy for childhood stuttering? Dissecting and reinterpreting the evidence in light of spontaneous recovery rates. International Journal of Language \& Communication Disorders. 2005; 40(3):359-74. [DOI:10.1080/13682820400027735] [PMID]

[12] Beitchman J, Brownlie E, Inglis A, Wild J, Ferguson B, Schachter D, et al. Seven-year follow-up of speech/language impaired and control children: Psychiatric outcome. Journal of Child Psychology and Psychiatry. 1996; 37(8):961-70. [DOI:10.1111/j.1469-7610.1996.tb01493.x] [PMID]

[13] Beitchman JH, Nair R, Clegg M, Ferguson B, Patel P. Prevalence of psychiatric disorders in children with speech and language disorders. Journal of the American Academy of Child Psychiatry. 1986; 25(4):528-35. [DOI:10.1016/S0002-7138(10)60013-1]

[14] Beitchman JH, Wilson B, Johnson CJ, Atkinson L, Young A, Adlaf E, et al. Fourteen-year follow-up of speech/languageimpaired and control children: Psychiatric outcome. Journal of the American Academy of Child \& Adolescent Psychiatry. 2001; 40(1):75-82. [DOI:10.1097/00004583-200101000-00019] [PMID]

[15] Millard SK, Edwards S, Cook FM. Parent-child interaction therapy: Adding to the evidence. International Journal of Speech-Language Pathology. 2009; 11(1):61-76. [DOI:10.1080/17549500802603895]

[16] Packman A. Theory and therapy in stuttering: A complex relationship. Journal of Fluency Disorders. 2012; 37(4):225-33. [DOI:10.1016/j.jfludis.2012.05.004] [PMID]

[17] Yaruss JS, Coleman C, Hammer D. Treating preschool children who stutter: Description and preliminary evaluation of a familyfocused treatment approach. Language, Speech, and Hearing Services in Schools. 2006; 37(2):118-36. [DOI:10.1044/01611461(2006/014)]

[18] de Sonneville-Koedoot C, Stolk E, Rietveld T, Franken MC. Direct versus indirect treatment for preschool children who stutter: The RESTART randomized trial. PIOS One. 2015;10(7):e0133758

[19] Guitar B. Stuttering: An integrated approach to its nature and treatment. Philadelphia: Lippincott Williams \& Wilkins; 2013.

[20] Behpajooh A, Kamali Sh. [Comparison of the effectiveness of clinical methods and self improvement in the treatment of stut- 
tering in children with speech disorder (Persian)]. Journal of Educational Sciences and Psychology. 2005; 3(2):65-90.

[21] Shafii B, Faramarzi S, Abedi A, Dehqan A, C sherer N. [Determining the effectiveness of direct, indirect and combined therapeutic therapy methods on pregnant children's stuttering stress (Persian)]. Jundishapur Scientific Medical Journal. 2018; 17(2):203-24

[22] Franken M-C, de Sonneville-Koedoot C, Stolk E, Rietveld A, Bouwmans-Frijters C. Comparing a demands and capacities model approach and the lidcombe program for pre-school stuttering children: The restart randomised trail. Procedia-Social and Behavioral Sciences. 2015; 193:287-8. [DOI:10.1016/j.sbspro.2015.03.276]

[23] Boucand VA, Millard S, Packman A. Early intervention for stuttering: Similarities and differences between two programs. SIG 4 Perspectives on Fluency and Fluency Disorders. 2014 24(1):8-19. [DOI:10.1044/ffd24.1.8

[24] Lambert MJ, Bergin AE. The effectiveness of psychotherapy. Handbook of psychotherapy and behavior change. Oxford, England: John Wiley \& Sons. 1994; 4:143-89.

[25] Asay TP, Lambert MJ. The empirical case for the common factors in therapy: Quantitative findings. Washington DC: American Psychological Association; 1999.

[26] Franken M-CJ, Kielstra-Van der Schalk CJ, Boelens H. Experimental treatment of early stuttering: A preliminary study. Journal of Fluency Disorders. 2005; 30(3):189-99. [DOI:10.1016/j. jfludis.2005.05.002] [PMID]

[27] Mollon B, Chong JJ, Holbrook AM, Sung M, Thabane L, Foster $\mathrm{G}$. Features predicting the success of computerized decision support for prescribing: A systematic review of randomized controlled trials. BMC Medical Informatics and Decision Making. 2009; 9(1):11. [DOI:10.1186/1472-6947-9-11] [PMID] [PMCID]

[28] Lewis C, Packman A, Onslow M, Simpson JM, Jones M. A Phase II trial of tele-health delivery of the Lidcombe Program of Early Stuttering Intervention. American Journal of SpeechLanguage Pathology. 2008; 17(2):139-49. [DOI:10.1044/10580360(2008/014)]

[29] O'Brian S, Smith K, Onslow M. Webcam delivery of the Lidcombe Program for early stuttering: A phase I clinical trial. Journal of Speech, Language, and Hearing Research. 2014; 57(3):825 30. [DOI:10.1044/2014_JSLHR-S-13-0094] [PMID]

[30] Wilson L, Onslow M, Lincoln M. Tele-health adaptation of the lidcombe program of early stuttering intervention five case studies. American Journal of Speech-Language Pathology. 2004; 13(1):81-92. [DOI:10.1044/1058-0360(2004/009)]

[31] Carey B, O'Brian S, Onslow M, Packman A, Menzies R. Webcam delivery of the Camperdown Program for adolescents who stutter: A Phase I trial. Language, Speech, and Hearing Services in Schools. 2012; 43(3):370-80. [DOI:10.1044/0161-1461(2011/110010)]

[32] O'Brian S, Packman A, Onslow M. Tele-health delivery of the Camperdown Program for adults who stutter: A phase I trial. Journal of Speech, Language, and Hearing Research. 2008; 51(1):184-95. [DOI:10.1044/1092-4388(2008/014)]

[33] Lei H, Nahum-Shani I, Lynch K, Oslin D, Murphy S. A" SMART" design for building individualized treatment sequences. Annual Review of Clinical Psychology. 2012; 8:21-48 [DOI:10.1146/annurev-clinpsy-032511-143152] [PMID] [PMCID]
[34] Hembree-Kigin TL, McNeil CB. Parent-child interaction therapy. Berlin: Springer Science \& Business Media; 2013.

[35] Pappas NW, McLeod S. Working with families in speech-language pathology. San Diego, CA: Plural Publishing; 2008.

[36] Riley GD, Bakker K. Stuttering severity instrument: SSI-4. Austin: Pro Ed; 2009.

[37] O'Brian S, Packman A, Onslow M, O'Brian N. Measurement of stuttering in adults: Comparison of stuttering-rate and severity-scaling methods. Journal of Speech, Language, and Hearing Research. 2004; 47(5):1081-7. [DOI:10.1044/1092-4388(2004/080)

[38] O'Brian S, Jones M, Packman A, Menzies R, Onslow M. Stuttering severity and educational attainment. Journal of Fluency Disorders. 2011; 36(2):86-92. [DOI:10.1016/j.jfludis.2011.02.006] [PMID]

[39] Eve CL, Onslow M, Andrews C, Adams R. Clinical measurement of early stuttering severity: The reliability of a 10-point scale. Australian Journal of Human Communication Disorders. 1995; 23(2):26-39. [DOI:10.3109/asl2.1995.23.issue-2.03]

[40] Onslow M, Harrison E, Jones M, Packman A. Beyond-clinic speech measures during the Lidcombe Program of early stuttering intervention. Acquiring Knowledge in Speech, Language and Hearing. 2002; 4(2):82-5.

[41] Onslow M, Andrews C, Costa L. Parental severity scaling of early stuttered speech: Four case studies. Australian Journal of Human Communication Disorders. 1990; 18(1):47-61 [DOI:10.3109/asl2.1990.18.issue-1.04]

[42] Shayan Sh, [Evaluation of clinical competencies of medical students using Electronic Patient Management Problem (EPMP) (Persian)]. Iranian Journal of Medical Education 2006; 10(5):65-90 
Appendix 1.

$$
\text { سناريو نمونه: }
$$

$$
\begin{aligned}
& \text { ( مادر على احساس مى كند على از اعتماد بنفس كافى در ارتباطاتش و بيان خواسته هايش با ديكران برخوردار نيست و مى ترسد } \\
& \text { كزينه اول لخ لـنتِ يك مشكل روانشناختى است كه در اثر ترس شديد در كودى ايجاد مى شود. }
\end{aligned}
$$

موافقم

\begin{tabular}{|c|c|c|}
\hline كرده ام. مورد را در مورد فرزندم مشاهده & اين مورد را مى دانستم & \\
\hline & & 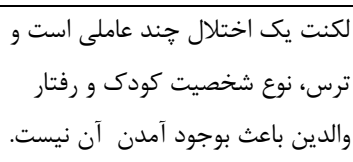 \\
\hline & & كنترل خود فرد نيست امرى ارادى است كه تحت \\
\hline
\end{tabular}

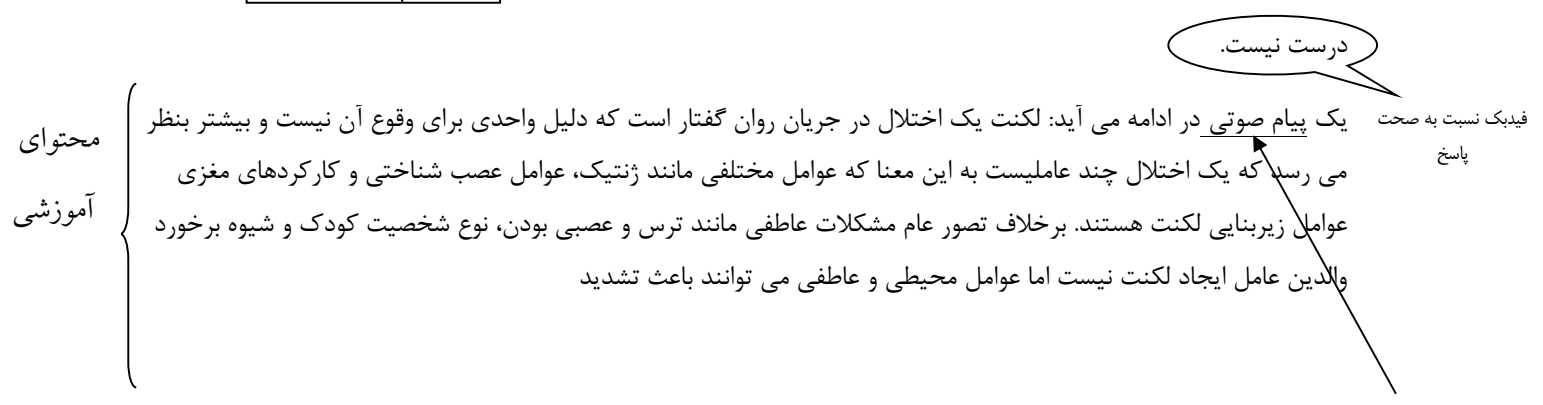

$$
\text { نوع كه براى آموزش هدف }
$$

انتخاب شده

در پايان اين سناريو جدولى به شكل زير به مراجع داده مى شود كه با يرسيدن سوالاتى به جمع بندى مباحث ارائه

$$
\text { شده مى يردازد. }
$$

